\title{
ENSURING THE REQUIRED LEVEL OF RELIABILITY DURING THE DESIGN STAGE OF -LATTICED SHELLS WITH A LARGE OPENING
}

\author{
Yevgen GOROKHOV, Volodymyr MUSHCHANOV, Iurii PRYADKO \\ Donbas National Academy of Civil Engineering and Architecture, Derzhavina Street, 2, \\ 86123, Makiyvka, Donetsk Region, Ukraine
}

Received 03 Feb 2014; accepted 17 Nov 2014

\begin{abstract}
The article describes the design technique, which is based on determination of numerical parameters pertaining to reliability of long-span latticed roofs with a large opening formed using the system made of rigid threads. The suggested algorithm is based on experimental and fundamental research focused on the stress/strain state of a spatial roof model and the operation of design combination of loads. It suggests a solution to a series of problems: determining rational geometric parameters for a structure; obtaining corresponding rigid characteristics of the principal load-bearing members; determining the trajectory of member failure for a typical shell structure with a resulting estimation of stress/ strain state of a structure; determining numerical parameters of reliability of a designed structure (determining the lower and upper limits of reliability). The proposed algorithm is limited by static loads and state requirements on strength limits. The example of a design for a spatial latticed shell formed using the system of flexurally stiff threads has been given according to the above-described algorithm.
\end{abstract}

Keywords: spatial suspended latticed roof, flexurally stiff threads, reliability parameters, stress/strain state (SSS), snow load.

\section{Introduction}

Nowadays, a great number of long-span roofs have been built. Each of them has a unique structural solution and a specific approach to the design of roof structures.

Load-bearing members of suspended roofs are frequently made of flexible or rigid thread, i.e. cables. Cables can be made out of ordinary rolled steel, reinforcing truss rods and high-strength wire and threads. Such roofs stand out among others by the absence of prestressing process and by the ability to obtain a relevant rigidity at a small dead load and big variable load. The material used in suspension shells operates in two directions; besides, suspension shells can react to shearing forces.

Long-span roofs have an increased level of liability, since their failures can lead to severe economic results and social consequences. Consequently, the design of these unique structures has to be based on a complex approach to the choice of a rational structural conception connected with functional appointment, architectural conception, manufacturing methods and erection, and specifications. Reliability requirements, adaptability to manufacture, economic efficiency, ecological and social factors should fully correspond to such national regulations as DBN B.2.6-163-2010 (2010) and DBN B.1.2-14-2009 (2009) in Ukraine or Eurocode 3 (EN 1993-1-1 2005) in the EU.
The basis for the design of shells was already established in the $19^{\text {th }}$ century. A considerable progress in the shell theory was achieved in the first half of the $20^{\text {th }}$ century. A great contribution to the theory of design of longspan spatial shells was made by a number of researchers. Mushchanov and Pryadko (2012) and Mushchanov and Rudneva (2012) are closely investigating this issue today.

One of the most important problems in the research of roofs in construction projects of increased liability is the probability estimation of their reliability. The principal property that determines the reliability of such structures is their failure-free operation: the ability to keep determined operational qualities during the determined service period. The quantitative characteristic of the given property is the probability of dependable operation, described by Pichugin (2009).

Current design standards do not contain requirements for quantitative estimation of reliability of longspan roofs. Design requirements are supposed to provide a sufficient level of reliability; however, this level can vary within wide range of limits depending on the variability characteristics of loads and material properties, structural schematic drawing, number of members in the structure, and dependence of forces particular to such members on various loads. 
Reliability of metal constructions used for buildings and structures, which represent statically determinate or indeterminate systems of members, was studied by numerous researchers who focused on separate problems and examples. Recently, new results in this area have been described by Kala (2007), Z. Kala and J. Kala (2009). In the determination of reliability parameters of unique structures, valuable results have been achieved by Guo et al. (2011), Kihyon and Frangopol (2010), and Wu et al. (2010).

Useful scientific experience in the field of structural reliability assessment has been gained by Luo et al. (2009), Chowdhury et al. (2009), and Xiao et al. (2011); and in the field of probabilistic interval reliability of structural systems - by Qiu et al. (2008).

Among articles dedicated to problems of reliability estimation of long-span suspension and cable structures, one can single out publications by Yeremeyev (2006) and Sventikov (2009).

In technical reliability theory, the reliability estimation of complex systems is usually reduced to consideration of two principal types of member connections (Pichugin 2009):

a) a series connection, probability of dependable operation at independent members is determined as:

$$
P_{m}=\prod_{i=1}^{m} P_{i},
$$

where $P_{i}$ is the probability of dependable operation of the element $i$;

b) a parallel connection:

$$
P_{m}=1-\sum_{i=1}^{m}\left(1-P_{i}\right) .
$$

In probabilistic sense, series connection can be applied for describing the operation of statically determinate systems, e.g. trusses.

However, practical estimation of reliability of real structures cannot be reduced to application of a simple Eqn (1) due to the presence of correlation between failure conditions of members.

Reliability design of statically indeterminate systems is usually carried out with the help of the following methods: the condition method, the probabilistic method of limit equilibrium, the Monte-Carlo calculation and Markov model of the reliability design (Shpete 1994; Balu, Rao 2013).

In suspension structures, operational load rests on the span formed by the system of flexurally stiff threads transmitted to the external and internal contours of the roof (Fig. 1). Therefore, a failure of the roof should be considered as a sequence of following events: the loss of stability or failure of suspension members, external and internal contours. Thus, suspension system represents a parallel connection of the above-mentioned members. Hence, the probability of roof non-failure in accordance with Eqn (2), can be written as (Mushchanov, Pryadko 2012):

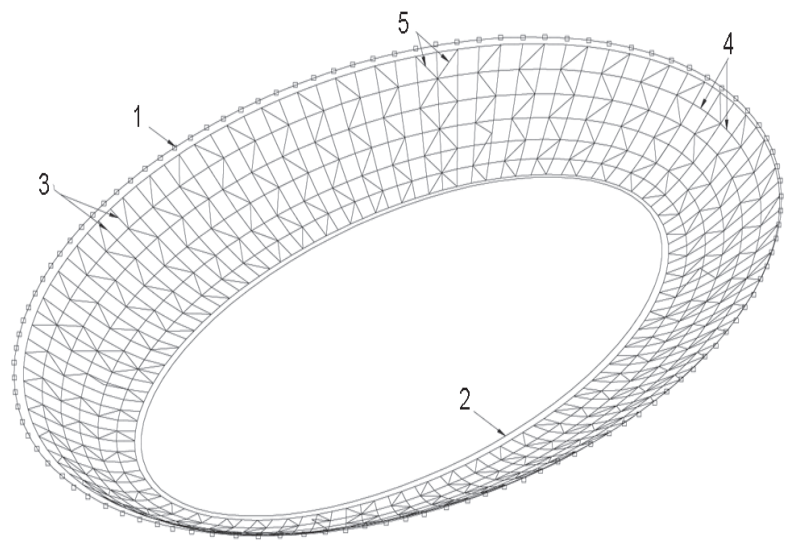

Fig. 1. Long-span latticed roof with a large elliptical opening: 1,2 - external and internal supporting contours; 3, 4, 5 radial, annular and diagonal members

$$
1-P_{\text {syst }}=\left(1-P_{\text {span }}\right) \times\left(1-P_{\text {ext.con. }}\right) \times\left(1-P_{\text {int.con. }}\right),
$$

where $P_{\text {syst }}, P_{\text {span }}, P_{\text {ext.con. }}, P_{\text {int.con. }}$ are failure probabilities pertaining to the roof system, load-bearing span members, internal and external contours, respectively.

Various approaches to provision of reliability of building design conceptions, particularly metal structures, have obtained nowadays significant development and justification. However, there are no convenient and sufficiently simple methods that could be used to determine evident reliability parameters for the considered structures at the design stage. Having been designed on the basis of the method of limit states, various structural conceptions cannot be compared with the reliability level of the design conception (Gorokhov et al. 2008).

These problems can be addressed with the help of a simplified method based on the application of an engineering design procedure for stress/strain state of the roof and preliminary refinement of the set of members determining the capacity for work and reliability of the system.

With regard to the above-mentioned information, the goal of this research is the design procedure for a sloping long-span suspension shell with an elliptical opening formed using the system of flexurally stiff threads of the through section, based on determination of numerical parameters pertaining to reliability of designed structure.

The design procedure of a spatial latticed shell with an elliptical opening can stipulate such problems as destination of initial geometric parameters of the roof, preliminary, fitting of the section with consequent more precise definition using a finite element model, which varies depending on different versions of loading. In addition, it addresses the key problem, which has not been earlier omitted from design work based on the method of limit states, namely, the numerical determination of reliability parameters pertaining to a multiple statically indeterminate system in the form of a suspension latticed shell with a large elliptical opening. 
Table 1. Correction factors $k_{\sigma}^{\prime}, k_{\sigma}^{\prime \prime}$

\begin{tabular}{l|c|c|c|c|c|c|c|c}
\hline \multirow{2}{*}{ Component } & \multicolumn{4}{|c|}{$k_{\sigma}^{\prime}$} & \multicolumn{4}{c}{$k_{\sigma}^{\prime \prime}$} \\
\cline { 2 - 11 } & \multicolumn{4}{|c|}{ Supports in one leve } & Difference in height & Thread along the long axis & \multicolumn{2}{c}{ Thread along the short axis } \\
\cline { 2 - 11 } & $\sigma-$ & $\sigma+$ & $\Sigma-$ & $\sigma+$ & $\sigma-$ & $\sigma_{+}$ & $\sigma_{-}$ & $\sigma_{+}^{+}$ \\
\hline Lower boom & - & 1.16 & - & 1.05 & 2.34 & 0.43 & - & 3.23 \\
\hline Upper boom & 1.12 & 1.00 & 0.93 & 1.11 & - & 3.33 & 9.11 & 1.00 \\
\hline Diagonal rod & 1.23 & 1.00 & 1.22 & 0.94 & 1.54 & 1.62 & 3.31 & 3.32 \\
\hline
\end{tabular}

There are three design stages described in the following section of the article.

\section{The design procedure}

\subsection{The first stage of the design procedure}

During the first stage of the design procedure, for assignment of initial rigidity characteristics, the engineering design of the roof is realized. Geometric and rigidity characteristics of the principal load-bearing structures of the roof are determined.

First of all, rigidity characteristics of a flexurally stiff thread are determined. Calculations are based on the procedures by Belenya et al. (1991) and Vedenikov and Teloyan (1997) with regard to more precise definition for through section trusses, which is outlined in works by Mushchanov and Gibalenko (1999) (Fig. 2).

The differential equation of the flexibly stiff thread balance:

$$
E I \frac{d w^{4}}{d x^{4}}-H \frac{d^{2}(f+\omega)}{d x^{2}}+q(x)=0 .
$$

On the basis of application of relations between the relative parameter of load $p^{*}$ and the parameter of relative sagging $\varphi$, the values of longitudinal force $N_{u b}$ and $N_{l b}$ of upper and lower boom:

$$
N_{l b} \approx N \cdot \frac{a_{l b}}{h}+\frac{M}{h} \cdot \alpha \cdot k ; N_{u b} \approx N \cdot \frac{a_{u b}}{h}+\frac{M}{h} \cdot \alpha,
$$

where: $\alpha$ takes into account redistribution of stresses between truss booms; $a_{u b}, a_{l b}$ are the distances from the cen-
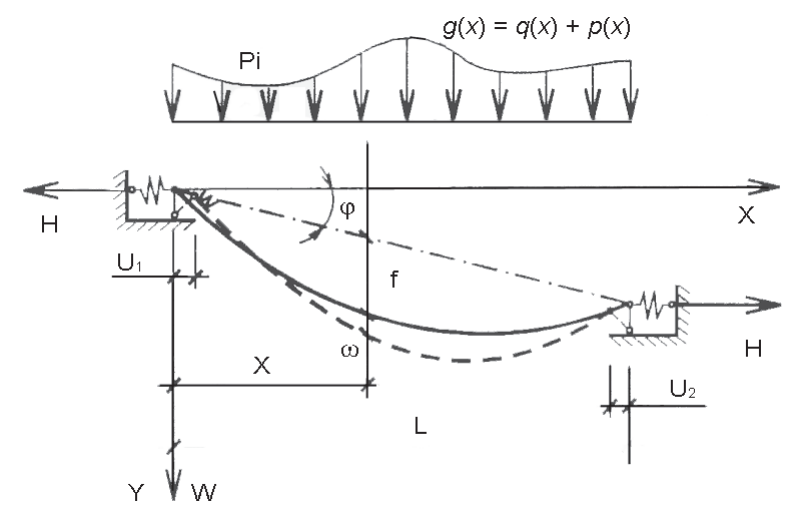

Fig. 2. Flexurally stiff thread design on refractory supports tre of gravity of sections of upper and lower boom to the centre of gravity of the combined section; $k$ considers the effect of bending moments stipulated by misalignment in sites.

Table 1 gives the correction factors $k_{\sigma}^{\prime}, k_{\sigma}^{\prime \prime}$ for bar members of the designed structure. The factors consider operation of truss members in the design of the spatial latticed shell.

Proximate stresses:

$N_{u b}^{y}=k_{\sigma}^{\prime} k_{\sigma}^{\prime \prime} N_{u b}, N_{l b}^{y}=k_{\sigma}^{\prime} k_{\sigma}^{\prime \prime} N_{l b}, N_{r}^{y}=k_{\sigma}^{\prime} k_{\sigma}^{\prime \prime} N_{r}$.

Having calculated the values of longitudinal stresses, the geometric characteristics of sections of truss members are determined.

In engineering design, based on application of the system of dimensionless spatially rigid parameters, the rational geometric parameters of the roof are determined and corresponding rigidity characteristics of principal loadbearing members are calculated. In engineering design, the following dimensionless parameters are accepted (Fig. 6): rigid parameters $\bar{D}_{1}=\left(E I_{z}^{e x t} a b_{1}^{4}+E I_{z}^{\text {int }} a_{1} b^{4}\right) / E t b^{4} b_{1}^{4}$ and $\bar{D}_{4}=E I_{y} b /\left(E t R^{2}\right)$, dimensionless parameters of the inner support contour displacement $\bar{W}=W / f$ and $\bar{U}=U / a$ horizontal displacement of the outer support contour $\bar{N}=N a b a^{2} / E A^{3}$, dimensionless parameter of longitudinal force and the dimensionless parameter of the dimensionless bending moment $\bar{M}=M a b / E I_{y} a$ (Fig. 3), which exclude the scale factor during the design.

Algorithm of the engineering design of the roof:

1. Geometrical parameters of the shell are set: $A_{r}$ is the stage of radial ribs, $A_{c}$ is the stage of circular ribs, $R$ is the curvature radius of the inner contour;

2. Snow load $S$ in $\mathrm{kg} / \mathrm{m}^{2}$ of the roof depending on regional snow data;

3. The dimension parameter $D_{4} \approx 0.012 \div 0.029$ is set;

4. $\bar{D}_{1}, \bar{W}, \bar{U}$ are defined due to the correspondence $\bar{W}=f\left(D_{1}, D_{4}\right), \bar{U}=f\left(D_{1}, D_{4}\right)$;

5. $\bar{N}, \vec{M}$ of the inner and outer contours are defined due to the correspondence $\overline{D_{1}}=f(\bar{M}, \bar{W}), \overline{D_{1}}=f(\bar{N}, \bar{W})$, $\overline{D_{1}}=f(\bar{M}, \bar{U}), \overline{D_{1}}=f(\bar{N}, \bar{U})$, (Fig. 3);

6 . The rigidity characteristics of radial, internal and external contours are calculated;

7. The test of the load-bearing ability pertaining to principal load-bearing members of the roof is performed. For further estimation of the reliability level pertain- 
a)

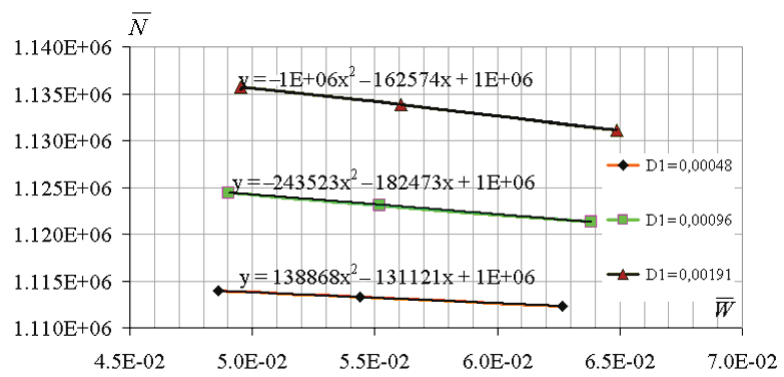

b)

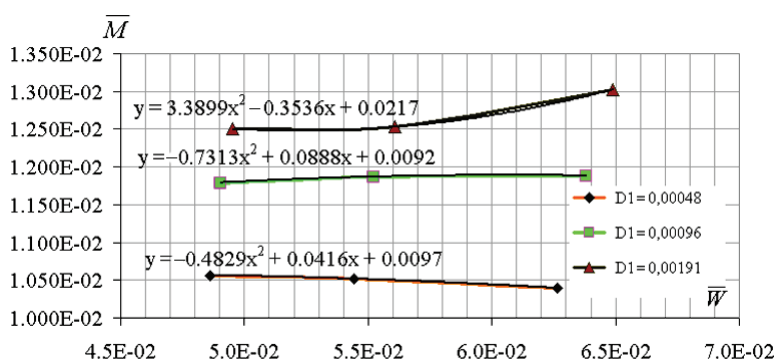

Fig. 3. Dependences of dimensionless parameters on the displacement: a) dependence of $\bar{N}(\bar{W})$ for the inner contour; b) dependence of $\bar{M}(\bar{W})$ for the inner contour

ing to construction element compounds of the outer and inner supporting contour, general regularities of inner tension changes in dependences of these members on geometrical and rigid parameters of the designed shell have been determined (Fig. 3).

\subsection{The second stage of the design procedure}

The purpose of the second stage of design is dedicated to numerical design and determining the trajectory of the roof system failure. In this case, the set of failed members, the aggregate behaviour of which determines the level of the upper limit of the reliability system.

The failure of tension members is fixed under the condition of excess yield stress and in case of compression members - buckling. It should be noted that at this point, a steel member does not fail but rather passes into the elastoplastic stage of deformation.

To determine the failure trajectory, SCAD software is used to perform the numerical stepwise calculation of the roof considering the geometric nonlinearity. In this case, it should be noted that based on the existing experience on such roofs, maximum stresses in members arise at uniformly distributed standard temporary snow load Sdesign for the considered part of a building. Value of snow load have been taken from DBN B.1.2-2:2006 (2006). In case none of the roof members fail, then the snow load is gradually increased and recalculation of the scheme is carried out.

Calculations result in determination of the failed roof member (Fig. 4). By keeping the same loading scheme and gradually removing failed elements, it is possible to determine the group of failed elements and the forecasted roof failure section.

The roof failure is considered to be the failure in the form of section I; since in subsequent loading, the avalanche failure of section II members takes place. The roof scheme with failed members of the span section indicates the most stressed members of the internal and external contours. The values of their maximum stresses $M$ and $N$ are also determined.

\subsection{The third stage of the design procedure}

The third stage is dedicated to the probability estimation of the roof, which determines the upper and lower limits of reliability (Mushchanov, Pryadko 2012).

Firstly, the lower limit of reliability for the roof construction is determined. A shell model with the sequential connection of members is used for calculations; consequently, it is supposed that should one of the members fail, it would initiate the failure mechanism in the whole construction (of the flexurally stiff thread in the through cross-section). In order to calculate the probable failure, the member that was the first to lose its bearing ability is taken as it is responsible for the destruction of the whole shell.

Numerical Monte-Carlo Method (MCM) is used as the basis for calculation as it solves probability problems with the help of statistic means. Random numbers serve as principle auxiliary means. As random quantities the cross-section area of the most strained member of the truss chord upper compression $\tilde{A}=Z_{1}$ and steel yield $\tilde{\sigma}_{m}=Z_{2}$ are used. The failure of the member occurs if $N_{\text {destr }}>\tilde{\sigma}_{m} * A$, where $N_{\text {destr }}$ is force, as a result of which yield limit is achieved. $N$ serves reliability calculations of the most strained thread member.

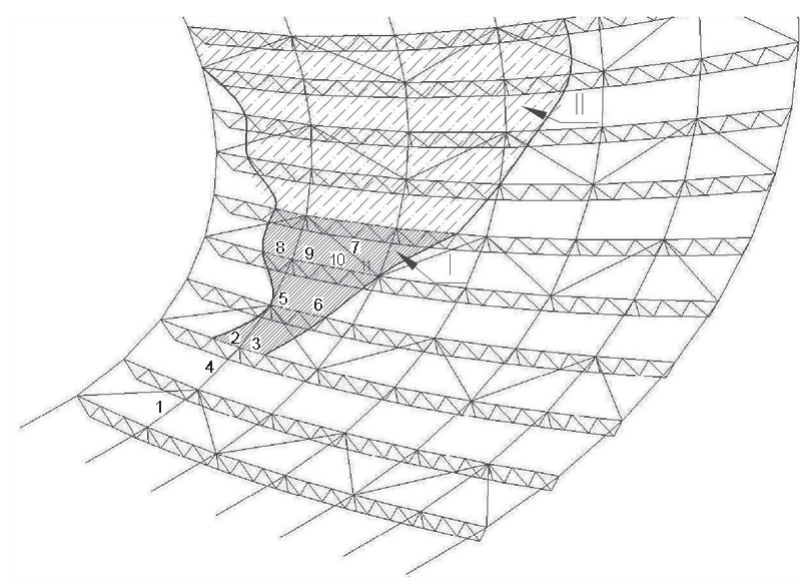

Fig. 4. Destructed shell area. Failure of members 1-11; I destructed section; II - predicted section of further destruction 
Thus, the equation of the critical stress is:

$$
g\left(Z_{1}, Z_{2}\right)=Z_{1} \cdot Z_{2}-N_{\text {destr }}=0
$$

In order to determine the probable failure frequency, random values of the cross-section area and allowed variable $Z_{1}$ and $Z_{2}$ are expressed by a random force value $\tilde{N}=Z_{1} \cdot Z_{2}$.

Tables 2 and 3 provide the probable failure values $P_{f}$ of the fixed member and the probability frequency distribution $N=Z_{1} \cdot Z_{2}$, obtained using the Monte-Carlo Calculations Method for different possible parameters of random values, stipulated based on statistical data collected at Ukrainian enterprises that produce rolled metal; and for different reserves of bearing ability expressed as $N / N_{0}$, where $N-$ the actual force determined in the destructed member and $N_{0}$ - calculated force, regulated by normative documents. The number of realised random numbers is $n=10000$. Table 3 demonstrates that for the considered class of structure responsibility CC3 the sequence of considered factors which indicated with a dark colour do not provide the required level of the element reliability.
Table 2 demonstrates that for the considered CC3 class of liability for constructions, the combination of factors under consideration marked in bold, do not provide the required level of member reliability.

Main random variables affecting the result are situated in the interval $[a ; b]$, the relative appearance frequency of which exceeds $0.05(5 \%)$; this leads to the conclusion that the interval will contain forces with a probability of $95 \%$.

The upper limit of reliability is determined based on results determining the failure trajectory of the roof and determined failed members.

Suspension system of the roof represents the parallel connection of principal load-bearing structures. Starting from it, probability of non-failure of the roof is written down as:

$$
1-P_{\text {syst }}=\left(1-P_{\text {span }}\right) \times\left(1-\mathrm{P}_{\text {ext.con. }}\right) \times\left(1-\mathrm{P}_{\text {int.con. }}\right),
$$

where $P_{\text {syst }}, P_{\text {span }}, P_{\text {ext.con. }}, P_{\text {int.con. }}$ are probability of failure of the roof system, spacing part, external and internal contours, respectively.

Table 2. Lower limit of reliability (failure probability of $P_{f}$ member)

\begin{tabular}{c|c|c|c|c|c|c}
\hline$N / N_{0}$ & \multicolumn{2}{|c|}{0.95} & \multicolumn{2}{|c|}{0.97} & \multicolumn{2}{c}{1} \\
\hline$\tilde{A} \tilde{\sigma}_{m}$ & $5 \%$ & $7 \%$ & $5 \%$ & $7 \%$ & $5 \%$ & $7 \%$ \\
\hline $3 \%$ & $5.2 \times 10^{-5}$ & $5.5 \times 10^{-5}$ & $5.7 \times 10^{-5}$ & $6.1 \times 10^{-5}$ & $7.3 \times 10^{-5}$ & $\mathbf{1 . 2}^{-5} \times \mathbf{1 0}^{-4}$ \\
$4 \%$ & $5.7 \times 10^{-5}$ & $5.9 \times 10^{-5}$ & $6.3 \times 10^{-5}$ & $7.6 \times 10^{-5}$ & $\mathbf{1 . 0} \times \mathbf{1 0}^{-4}$ & $\mathbf{2 . 2} \times \mathbf{1 0}^{-4}$ \\
$5 \%$ & $6.1 \times 10^{-5}$ & $6.6 \times 10^{-5}$ & $7.9 \times 10^{-5}$ & $9.4 \times 10^{-5}$ & $\mathbf{1 . 8}^{-5} \times \mathbf{1 0}^{-4}$ & $\mathbf{2 . 9}^{-4} \times \mathbf{1 0}^{-4}$ \\
\hline
\end{tabular}

\begin{tabular}{|c|c|c|}
\hline \multicolumn{3}{|c|}{$N / N_{0}=0.95$} \\
\hline$\tilde{A}$ & $5 \%$ & $7 \%$ \\
\hline $3 \%$ & $y=2 E-06 x^{4}-9 E-05 x^{3}+0.0043 x^{2}-0.0287 x+0.007$ & $y=8 E-07 x^{4}-7 E-05 x^{3}+0.0032 x^{2}-0.0143 x+0.0012$ \\
\hline $4 \%$ & $y=7 E-07 x^{4}-6 E-05 x^{3}+0.00022 x^{2}-0.0076 x+0.006$ & $y=5 E-07 x^{4}-6 E-05 x^{3}+0.00012 x^{2}-0.0054 x+0.0032$ \\
\hline $5 \%$ & $y=9 E-08 x^{4}-1 E-05 x^{3}+0.0009 x^{2}-0.0022 x+0.01$ & $y=8 \mathrm{E}-08 \mathrm{x}^{4}-9 \mathrm{E}-06 \mathrm{x}^{3}+0.0005 \mathrm{x}^{2}+0.0008 \mathrm{x}+0.0032$ \\
\hline \multicolumn{3}{|c|}{$N / N_{0}=0.97$} \\
\hline$\tilde{A}$ & $5 \%$ & $7 \%$ \\
\hline $3 \%$ & $y=8 E-07 x^{4}-7 E-05 x^{3}+0.0025 x^{2}-0.0237 x+0.0036$ & $y=5 E-07 x^{4}-5 E-05 x^{3}+0.0012 x^{2}-0.0121 x+0.0131$ \\
\hline $4 \%$ & $y=5 E-07 x^{4}-4 E-05 x^{3}+0.0009 x^{2}-0.0056 x+0.022$ & $y=4 E-07 x^{4}-4 E-05 x^{3}+0.0005 x^{2}-0.0023 x+0.0042$ \\
\hline $5 \%$ & $y=7 E-08 x^{4}-9 E-06 x^{3}+0.0003 x^{2}-0.002 x+0.0027$ & $y=6 \mathrm{E}-08 \mathrm{x}^{4}-7 \mathrm{E}-06 \mathrm{x}^{3}+0.0001 \mathrm{x}^{2}+0.0007 \mathrm{x}+0.001$ \\
\hline \multicolumn{3}{|c|}{$N / N_{0}=1$} \\
\hline$\tilde{A}$ & $5 \%$ & $7 \%$ \\
\hline $3 \%$ & $y=5 E-07 x^{4}-5 E-05 x^{3}+0.0016 x^{2}-0.0132 x+0.025$ & $y=2 E-07 x^{4}-2 E-05 x^{3}+0.0007 x^{2}-0.0049 x+0.0111$ \\
\hline $4 \%$ & $y=2 E-07 x^{4}-2 E-05 x^{3}+0.0005 x^{2}-0.0025 x+0.0052$ & $y=1 E-07 x^{4}-1 E-05 x^{3}+0.0003 x^{2}-0.001 x+0.0062$ \\
\hline $5 \%$ & $y=4 E-08 x^{4}-5 E-06 x^{3}+0.0001 x^{2}-7 E-05 x+0.0089$ & $y=3 E-08 x^{4}-3 E-06 x^{3}+5 E-05 x^{2}+0.0008 x+0.0071$ \\
\hline
\end{tabular}

Table 3. Probability frequency distribution $N=Z_{1} \cdot Z_{2}$ 
To determine the reliability parameters of fixed members of trusses, external and internal contours the probability calculation is made with the help of an engineering technique. The flowchart for determining the upper limit of reliability is shown in Figure 5.

The research results were used during the technical state monitoring of the stadium "Donbas-Arena" in Donetsk, Ukraine at the operational stage (Report on the results of monitoring metal bearing structures of the shell. "Donbas-Arena" Stadium 2010).

Let us consider the example of the developed algorithm (Fig. 6).

\section{Conclusions}

1. Based on the results of the carried out research, the procedure has been worked out for determining reliability parameters of roof structure in the form of a long-span sloping suspension shell with an elliptical opening, per- mitting to calculate the upper and lower limit of reliability levels of the designed roof.

2. The worked out procedure can be used to determine reliability parameters of structural scheme types particular to long-span roofs different from the considered ones; however in this case, there is no possibility to use determined relationships to find the upper and lower limits, which requires an additional numerical calculation.

3. In the worked out procedure, the calculation of failure probability is based on the limits of load-bearing capacity of structural elements; that is the most important condition for assurance of their reliability. However, for the systems designed on the basis of demands of the second limit state, this can lead to significant reserves in calculated values of the upper and lower reliability limits. This is one possibility for subsequent improvements of the proposed procedure.

\section{External and internal contours loading $\tilde{S}$ is appointed for the selected building section. In this case, the density function of the random process is accepted according to the polynomial exponential law:}

$$
f_{n S}(\gamma)=\exp \left[C_{0}+C_{1} \cdot \gamma+C_{2} \cdot \gamma^{2}+C_{3} \cdot \gamma^{3}\right] .
$$

2. Distribution parameters of the random variable pertaining to the cross-section area $\tilde{A}$ of the contours described by the normal law are appointed.

3. According to the prescribed $\tilde{A}$, the value of the random variable of dimensionless parameter is calculated:

$$
\overline{\tilde{D}}_{1}=\left(E I_{z}^{e x t} a b_{1}^{4}+E I_{z}^{\text {int }} a_{1} b^{4}\right) / E t b^{4} b_{1}^{4}
$$

4. Random values of displacements $\overline{\tilde{\bar{W}}}$ and $\overline{\tilde{U}}$ are determined according to the prescribed value $\mathrm{g} / \mathrm{s}$ ( $\mathrm{g}$ is the constant load, $\mathrm{S}$ is the variable load) and $\overline{\tilde{D}}_{1}$.

5. Relations of dimensionless parameters (Fig. 3) are used to calculate values of random variables of dimensionless parameters of stresses $\bar{N}$ and $\bar{M}$.

6. The random variable of normal stresses is calculated:

$$
\tilde{\sigma}=\tilde{N} /(\phi \tilde{A})+\tilde{M} / \tilde{W} .
$$

7. Appointing distribution parameters of the random variable pertaining to the yield point of steel $\tilde{\sigma}_{y}$ depending on the chosen contour described by the normal law.

8. Reliability parameters:

- Rzhanitsin's reliability index:

$$
\begin{aligned}
& \gamma=\left(\bar{\sigma}_{y}-\bar{\sigma}\right) / \sqrt{\bar{\sigma}_{y}+\bar{\sigma}} \\
& -P_{\text {ext.con }}, P_{\text {int.con. }}
\end{aligned}
$$

\section{Span sectio}

1. Distribution parameters of random variables of longitudinal force $\bar{N}$ pertaining to failed roof elements are determined. The density function of random process is accepted in accordance to the polynomial exponential law:

$$
f_{n S}(\gamma)=\exp \left[C_{0}+C_{1} \cdot \gamma+C_{2} \cdot \gamma^{2}+C_{3} \cdot \gamma^{3}\right] .
$$

2. Distribution parameters (mean and standard deviation) of the random variable pertaining to the cross-section area $\tilde{A}$ of elements is described by normal law.

3. Correlation coefficient of dependence $\rho_{i, j}=e^{-x}$ between stresses in considered elements $i, j$, where $i \neq \mathrm{j}, x=|i-j|$.

4. Having determined parameters $\bar{N}$, the random variables of normal stresses are calculated:

$$
\tilde{\sigma}=\tilde{N} /(\phi \tilde{A})+\tilde{M} / \tilde{W} .
$$

5. The reliability parameters are calculated

- Rzhanitsin's reliability index:

$$
\gamma=\left(\bar{\sigma}_{y}-\bar{\sigma}\right) / \sqrt{\bar{\sigma}_{y}+\bar{\sigma}}
$$

$-P_{i}, P_{j}$;

- $P_{\text {span }}=\sum_{i=1}^{n} \sum_{j=1}^{m} P_{i} \cdot P_{j} \cdot \rho_{i j}$.

Fig. 5. Determination of the upper limit of reliability of a roof system 
Structural scheme of the spatial lattice shell

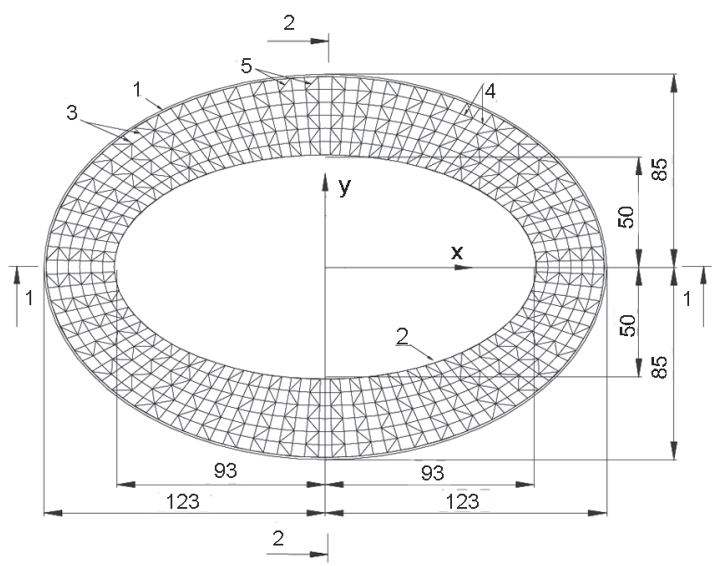

1,2 - external and internal contours;

$3,4,5$ - radial, circular and diagonal members. $\underline{1-1}$

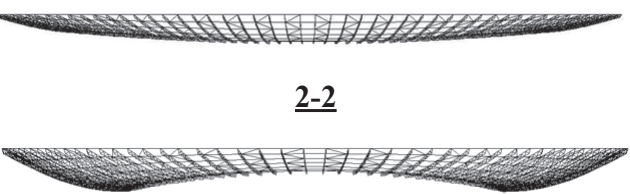

Distribution of random variable of snow load, $\mathrm{kg} / \mathrm{m}^{2}$

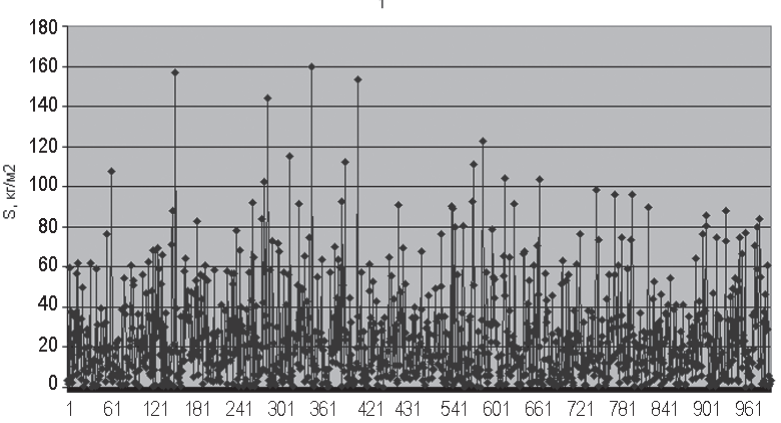

Rigidity characteristics of load-bearing members of designed roof

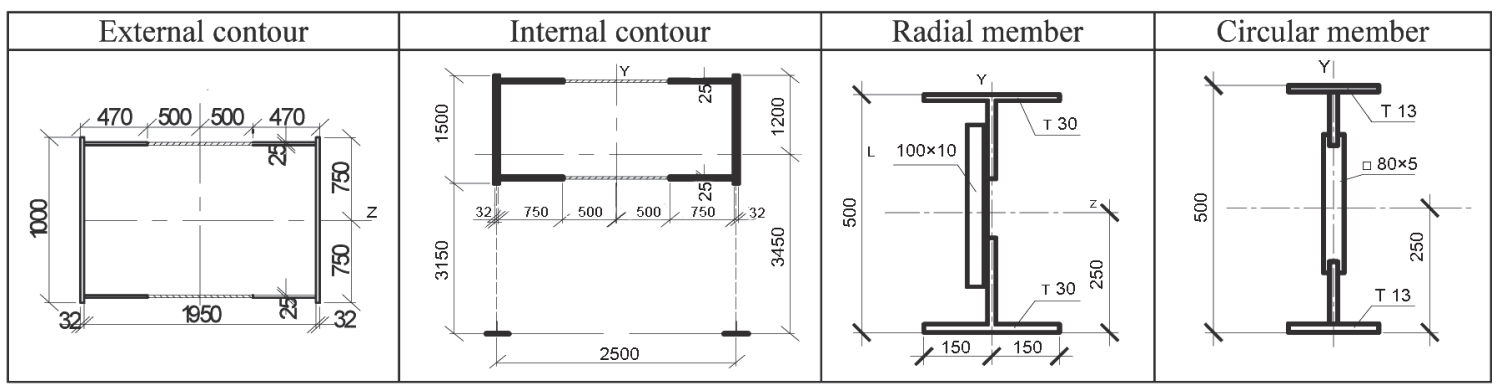

2-2 (deformed shape)

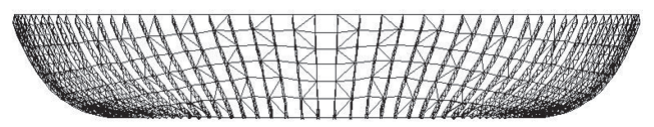

Failed section of the roof

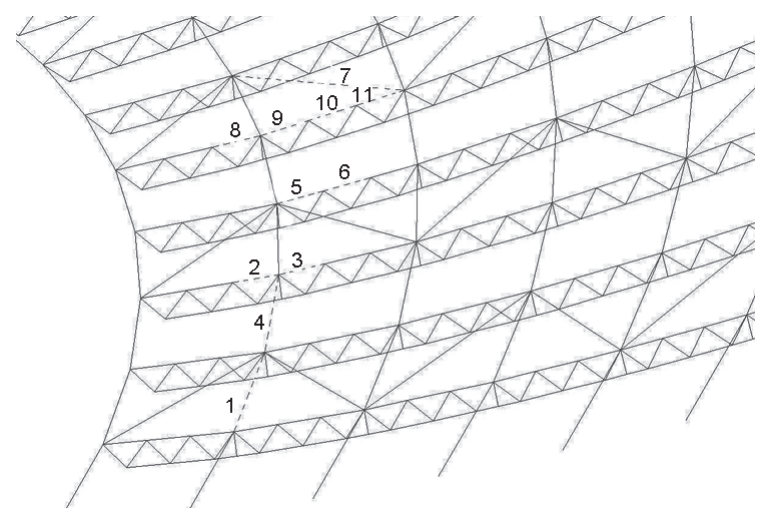

Lower limit of reliability

$\mathrm{y}=3 \mathrm{E}-08 \mathrm{x}^{4}-3 \mathrm{E}-06 \mathrm{x}^{3}+5 \mathrm{E}-05 \mathrm{x}^{2}+0.0008 \mathrm{x}+0.0071$

Probability failure $P_{f}=2.7 * 10^{-4}>P_{f(r e q)}=1 * 10^{-4}$
Zones of maximum stresses and deformations

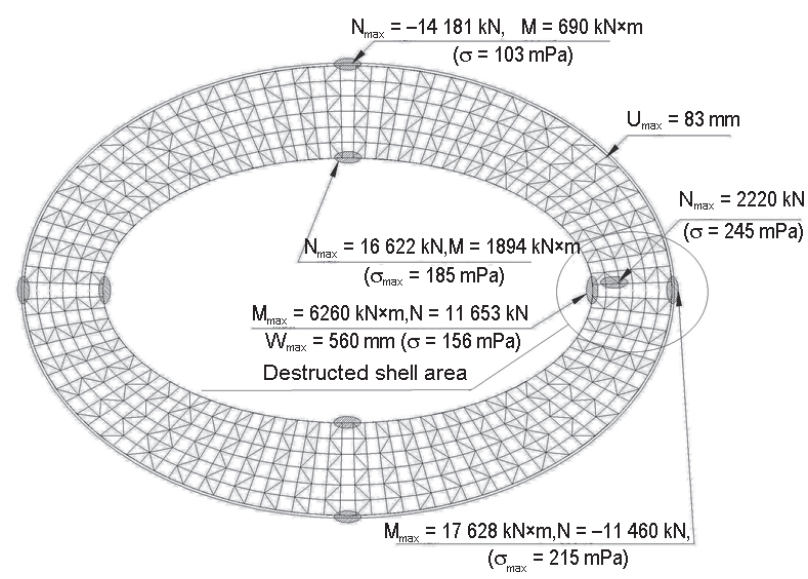

Upper limit of reliability

\begin{tabular}{c|c|c|c|c}
\hline \multirow{2}{*}{$\boldsymbol{P}_{\boldsymbol{f}}$} & \multicolumn{3}{|c|}{ Elementary } & \multirow{2}{*}{ System } \\
\cline { 2 - 4 } & Span & $\begin{array}{c}\text { External } \\
\text { contour }\end{array}$ & $\begin{array}{c}\text { Internal } \\
\text { contour }\end{array}$ & \\
\hline$P_{f}$ & $1.3^{*} 10^{-8}$ & $4.6^{*} 10^{-9}$ & $1.1 * 10^{-9}$ & $1.78^{*} 10^{-8}$ \\
\hline$P_{f(r e q)}$ & \multicolumn{3}{|c|}{$1 * 10^{-4}$} & $1 * 10^{-5}$ \\
\hline
\end{tabular}

Fig. 6. Example of the design of lattice shell with an elliptical opening formed using the system of rigid threads of the through section 


\section{References}

Balu, A. S.; Rao, B. N. 2013. Confidence bounds on design variables using high-dimensional model representation-based inverse reliability analysis, Journal of Structural Engineering 139(6): 985-996.

http://dx.doi.org/10.1061/(ASCE)ST.1943-541X.0000709

Belenya, E. I.; Streletsky, N. N.; Vedenikov, G. S.; Klepikov, L. V.; Morachevsky, T. N. 1991. Metal structures. Specialized course. Moscow. $687 \mathrm{p}$.

Chowdhury, R.; Rao, B. N.; Prasad, A. M. 2009. High-dimensional model representation for structural reliability analysis, Communications in Numerical Methods in Engineering 25(4): 301-337. http://dx.doi.org/10.1002/cnm.1118

DBN B.1.2-2:2006. National structural rules and regulations. The system of reliability and safety provision of constructional projects. Loads and effects. Kyiv, Ukraine, 2006. $61 \mathrm{p}$.

DBN B.1.2-14-2009. National structural rules and regulations. The system of reliability and safety provision of constructional projects. General principles of reliability control and constructional safety of buildings, structures and supports. Kyiv, Ukraine, 2009. 37 p.

DBN B.2.6-163-2010. National structural rules and regulations. The system of reliability and safety provision of constructional projects. steel structures. Kyiv, Ukraine, 2010. $224 \mathrm{p}$.

EN 993-1-1 Eurocode 3: Design of steel structures - Part 1-1: General rules and rules for buildings. Brussels: European Committee for Standardization, 2005. 91 p.

Gorokhov, Y. V.; Mushchanov, V. F.; Kinash, R. I.; Shimanovsky, A. V.; Lebedich, I. N. 2008. Structures of fixed-site shells over stadium stands. $2^{\text {nd }}$ ed. Makeyevka. $404 \mathrm{p}$.

Guo, T.; Sause, R.; Frangopol, D. M.; Li, A. 2011. Time-dependent reliability of psc box-girder bridge considering creep, shrinkage, and corrosion, Journal of Bridge Engineering 16(1): 29-43.

http://dx.doi.org/10.1061/(ASCE)BE.1943-5592.0000135

Kala, Z. 2007. Influence of partial safety factors on design reliability of steel structures - probability and fuzzy probability assessments, Journal of Civil Engineering and Management 13(4): 291-296.

Kala, Z.; Kala, J. 2009. Sensitivity analysis of stability problems of steel structures using shell finite elements and nonlinear computation methods, WSEAS Transactions on Applied and Theoretical Mechanics 4(3): 105-114.
Kihyon, K.; Frangopol, D. M. 2010. Bridge fatigue reliability assessment using probability density functions of equivalent stress range based on field monitoring data, International Journal of Fatigue 32(8): 1221-1232. http://dx.doi.org/10.1016/j.ijfatigue.2010.01.002

Luo, Y.; Kang, Z.; Li, A. 2009. Structural reliability assessments based on probability and convex set mixed model, Computers \& Structures 87(21-22): 1408-1415. http://dx.doi.org/10.1016/j.compstruc.2009.06.001

Mushchanov, V. F.; Gibalenko, V. A. 1999. Peculiar properties of real work operation and design of rigid cords of an open overcut, Ukraine Construction 5(1): 45-48.

Mushchanov, V. F.; Pryadko, Y. N. 2012. Total algorithm of safety index of overhanging coating formed by rigid cords of through section, Metal Structures 18(3): 159-169.

Mushchanov, V. F.; Rudneva, I. N. 2012. Stress-deformed state of a suspended system of bending-rigid fibers in terms of the support pliability, Metal Structures 18(1): 5-16.

Pichugin, S. F. 2009. Durability of steel structures of industrial buildings. Poltava, Ukraine. $452 \mathrm{p}$.

Qiu, Z.; Yang, D.; Elishakoff, I. 2008. Probabilistic interval reliability of structural systems, International Journal of Solids and Structures 45(10): 2850-2860. http://dx.doi.org/10.1016/j.ijsolstr.2008.01.005

Report on the results of monitoring metal bearing structures of the shell. "Donbas-Arena" Stadium. 2010. Makiyivka, Ukraine. 90 p.

Shpete, G. 1994. Durability of supporting building structures. Moscow. 288 p.

Sventikov, A. A. 2009. Reliability analysis of suspension rod coverings with the development of plastic deformation, in Collection of Scientific Articles of Central Research Institute of Kucherenko, Ukraine, 12-21.

Vedenikov, G. S.; Teloyan, A. L. 1997. Nonlinear method of analysis of bending and hard stay ropes, Building Mechanics and Analysis of Structures 6(1): 47-50.

Xiao, N. C.; Huang, H. Z.; Wang, Z.; Pang, Y.; He, L. 2011. Reliability sensitivity analysis for structural systems in interval probability form, Structural and Multidisciplinary Optimization 44(5): 691-705. http://dx.doi.org/10.1007/s00158-011-0652-9

Wu, Z.-J.; Wang, S.-L.; Ge, X.-R. 2010. Application of Latin hypercube sampling technique to slope reliability analysis, Yantu Lixue/Rock and Soil Mechanics 31(4): 1047-1054.

Yeremeyev, P. G. 2006. Design Peculiarities for Unique LargeSpan Buildings and Structures, Modern Industrial and Civil Construction 2(1): 5-15.

Yevgen GOROKHOV. Dr Sc., Professor, Head of the Metal Structure Department of Donbas National Academy of Civil Engineering and Architecture. Doctor of technical sciences, 1992. Rector at DonNACEA. Research interests: a complex evaluation of technical condition, operation, durability and reliability of metal structures of buildings and structures; concept development and registration systems for monitoring of the technical condition of buildings and structures.

Volodymyr MUSHCHANOV. Dr Sc., Professor, Head of the Theoretical and Applied Department of Donbas National Academy of Civil Engineering and Architecture. Doctor of technical sciences, 1997. Vice Rector for Research activity at DonNACEA. Research interests: new methods of calculation and design of thin-walled spatial structures in the form of large-shells; probabilistic analysis of stress-strain state in the form of the finite element method; engineering methods for assessing of the structures reliability.

Iurii PRYADKO. PhD Eng. at Fundamental and Applied Mechanics department of Donbas National Academy of Civil Engineering and Architecture (DonNACEA). Research interests: metal structures, design technique and design work, mathematical analysis, testing of buildings and structures, computer modeling of building structures, building materials, inspection of the building structures. 